\title{
The Effect of the 3-step Health Education and Tele-coaching Program for the Disabled People with Hypertension in Rural Regions
}

\author{
Hyunli Kim ${ }^{1}$, Soeun Park ${ }^{1}$, Kyungok Ju${ }^{1}$, Myungsuk Lee ${ }^{1}$ and Mi Sook, Jung ${ }^{1}$ \\ 1, First Author Professor, Chungnam National University,hlkim@cnu.ac.kr \\ 1,Corresponding Author Instructor, Chungnam National University, parkse@cnu.ac.kr \\ ${ }^{1}$ Instructor, Chungnam National University, jko2080@hanmail.net \\ ${ }^{1}$ Instructor, Chungnam National University, leems1223@hanmail.net \\ ${ }^{1}$ Assistant Professor, Chungnam National University, msjung@cnu.ac.kr
}

\begin{abstract}
Purpose: The purpose of this study was to evaluate the effectiveness of the 3-step health education and tele-coaching program for the disabilities with hypertension in rural regions. Method: The interrupted time series/quasi-experimental study of one group was conducted for 15 months at the rural community health center. The 3-step health education and telecoaching program was given to participants during 15months. Results: There were significant changes in self-management $(F=3.406, p<.01)$ and preferred salt concentration $(F=6.388, p<.001)$ between baseline assessment and other time points. No significant changes in systolic and diastolic blood pressure were found between each time point and these physiological indicators were within a normal range over time. Conclusion: The tailored program for disabled people with hypertension is very effective in improving healthrelated behaviors regarding salt restriction and self-management of hypertension.
\end{abstract}

Keywords: Disabilities, Health education, Tele-coaching program, Rural region

\section{Introduction}

Physically disabled people may suffer from chronic disease in addition to their innate/acquired disabilities [1]. The Korean Institute for Health and Social Affairs reported that about $70 \%$ of disabled individuals had chronic health problems such as vascular diseases or musculoskeletal disorders. Specifically, the four most prevalent chronic diseases in this group of people were hypertension (33.5\%), degenerative arthritis (10.3\%), diabetes (8.9\%), and stroke (7.7\%) [2]. Chronic diseases such as hypertensive vascular disorders can cause other serious health problems that often lead to short-term disabilities or long-term impairments in sensory, perceptual, and motor functions. According to the latest available national statistics, the $81 \%$ of stroke-induced disability had chronic diseases prior to brain attacks [2]. With consideration for the prevalence rates of physical disability and functional limitation caused by these chronic diseases, people with functional disabilities tend to be exposed to risk factors of generating at least one additional attack on physical, psychological, and cognitive dysfunction. For this reason, disabled people who still have comorbidity and premorbid health problems need to be treated as a target group at a high risk of relapse.

The number of disabled people aged 50 years and older increased up to $70 \%$ in 2011 [2]. Notably, the proportion of disabled people in rural areas was higher than that in urban areas and rural residents might have limited chances to receive self-care educations and professional practices from community healthcare providers [3]. These reflect that old people who have functional disabilities as well as reside in rural areas may have actual needs about 
health education and information for managing their chronic diseases and preventing secondary complications and disabilities.

Hypertension has been paid public attention due to the severity of health problems caused by uncontrolled hypertension. A close connection between high blood pressure and the occurrence of cerebral vascular accidents and/or cardiovascular disease has been well known [4]. Active treatment of uncontrolled high blood pressure reduces the risk of recurrent stroke by more than a quarter [5]. The improvement of self-monitoring skills through patient education and nurse-led telephone support may be an effective way to maintain a normal range of blood pressure and promote healthy lifestyles such as regular exercise, low-sodium diet, self-monitoring of blood pressure, and medication adherence $[3,6,7]$.

Various interventions for people with hypertension were developed in clinical and community settings [8-14]. However, there were no therapeutic programs that help health care professionals use to enhance the level of self-management in people who had both physical disabilities and uncontrolled hypertension in rural areas. Therefore, the purposes of the study were to develop the 3-step health education and tele-coaching program to manage hypertension and to evaluate the effectiveness of this self-management program in rural residents with hypertension.

\section{Method}

\subsection{Design and Sample}

We conducted an interrupted times series/quasi-experimental study of one group for 15 months from September, 2011 to December, 2012. This study was conducted at community health care center in OO-gun in Korea and all participants provided written informed consents. Fifty seven participants were enrolled at the baseline assessment, 47 participants were included at the second program and the third program, and 15 participants finally completed the third program over 15 months. The 3 -step health education and tele-coaching program consisted of three steps, and it is started with baseline assessment in September, 2011.

\subsection{Intervention}

The 3-step health education and tele-coaching program consisted of three steps. The step 1 started in November, 2011, and the step 2 was provided four months later on April, 2012, and we gave the last intervention in November, 2012 again. Each step consisted of six weekly education sessions of one hour duration. Research nurses made a call to each study participant and provided tele-coaching about the content of previous education and individual behavioral counseling in relation to difficulties in changing their lifestyles between each session. In addition to the baseline assessment, pre and post assessment was completed before and after each step.

\subsection{Measures}

Data were collected using a self-report questionnaires to assess self-management for hypertension, self-evaluation of salt intake, and demographic and medical characteristics. The blood pressure was measured by the research nurses on community health center with an automatic machine (Omron HEM-770A, Omron Healthcare Co., Ltd, Japan). To measure the preferred salt concentration, we prepared the bean sprout soup without salt at each time points, and asked each participant to add salt to suit their taste. After adding salt, we used the digital salt tester (Digital Handheld Salt Tester, DMT-20, http;//dyscale.co.kr) to measure the preferred salt concentration of each participant. 


\subsection{Analyses}

The collected data were analyzed using SPSS version 20.0. A repeated measures analysis of variance was performed to examine the changing pattern of outcome variables over time and a paired t-test was used to compare the differences of outcomes between each time points.

\section{Results}

\subsection{Characteristics of Participants}

This study included fifteen disabled participants. The mean age of the participants was 67 years and only $20 \%$ of them graduated from high school. Major cause of disability was disease (86.7\%), especially cardiovascular accident (47\%). The average duration of disability was 14 years. All participants had hypertension and they had additional comorbid condition such arthritis (53\%), diabetes (40\%), and cardiovascular disease (27\%) as seen in Table 1.

\subsection{Study Outcomes}

Significant changes in self- management were found between baseline assessment and other time points $(\mathrm{F}=3.406, p=<.01)$. The self-management scores following the second and the third session were not significantly lower than that of right after the first session intervention (Table 2). There were significant changes between the baseline assessment and other time points on preferred salt concentration $(\mathrm{F}=6.388, p<.001)$. And the effect of intervention on preferred salt concentration was found across time points except for the fourth time point $(\mathrm{p}=.073)$ rather than baseline. Salt concentration four month following the first session of intervention increased as compared with that immediately after the first intervention but the difference was marginally insignificant $(\mathrm{p}=.067)$. And salt concentration six month following the second session did not significantly increase as compared with that immediately after the second intervention $(\mathrm{p}=.452)$ (Table 2, Figure 1(b)).

Systolic and diastolic blood pressure did not show significant differences over time. They remained within a normal range than baseline assessment despite of a seasonal effect of cold weather during the winter(Figure 1(c), 1(d)). As presented in Table 3, self-evaluation of salt intake level dropped immediately following each program but there were no significant differences $(\mathrm{F}=1.560, p=.169)$.

Table 1. Socio-demographic and Disability Related Characteristics of the Participants

\begin{tabular}{|c|c|c|c|}
\hline Characteristic & & $\mathrm{No}(\%)$ & Mean(SD), year \\
\hline Age & & & $67.53(7.71)$ \\
\hline Gender & Male & $6(40.0)$ & \\
\hline \multirow{4}{*}{ Education level } & Female & $9(60.0)$ & \\
\hline & Illiteracy & $3(20.0)$ & \\
\hline & Elementary school & $6(40.0)$ & \\
\hline & Middle school & $3(20.0)$ & \\
\hline \multirow{4}{*}{ Marital status } & High school & $3(20.0)$ & \\
\hline & Married & $10(66.7)$ & \\
\hline & Divorce & $1(6.7)$ & \\
\hline & Bereaved & $4(26.7)$ & \\
\hline
\end{tabular}




\begin{tabular}{|c|c|c|c|}
\hline \multirow[t]{3}{*}{ Economic status } & High & $1(6.7)$ & \\
\hline & Middle & $8(53.3)$ & \\
\hline & Low & $6(40.0)$ & \\
\hline \multirow[t]{2}{*}{ Types of disability } & Physical & $8(53.3)$ & \\
\hline & CVA & $7(46.70)$ & \\
\hline \multirow[t]{2}{*}{ Cause of disability } & Accident & $2(13.3)$ & \\
\hline & Disease & $13(86.7)$ & \\
\hline \multirow{3}{*}{ Duration of disability } & $\geq$ 1year, < 10years & $7(46.9)$ & \\
\hline & $\geq 10$ years, $<20$ years & $5(33.5)$ & \\
\hline & $\geq 20$ years & $3(20.1)$ & $14.31(14.38)$ \\
\hline \multirow{4}{*}{$\begin{array}{l}\text { Accompanied disease } \\
\text { (Multiple response) }\end{array}$} & Hypertension & $15(100.0)$ & \\
\hline & Cardiovascular disease & $3(26.6)$ & \\
\hline & $\mathrm{DM}$ & $6(39.9)$ & \\
\hline & Arthritis & $8(53.3)$ & \\
\hline
\end{tabular}

Table 2. Comparison of Mean on Self-management, Preferred Salt Concentration and Self- evaluation of Salt Intake

\begin{tabular}{c|c|c|c|c|c|c}
\hline \multirow{2}{*}{ Time points } & \multicolumn{2}{|c|}{ Self- management } & \multicolumn{2}{c|}{$\begin{array}{c}\text { Preferred salt } \\
\text { concentration }\end{array}$} & \multicolumn{2}{c}{$\begin{array}{c}\text { Self- evaluation of salt } \\
\text { intake }\end{array}$} \\
\cline { 2 - 7 } & $\begin{array}{c}\text { Mean } \\
\text { (SD) }\end{array}$ & $\begin{array}{c}\text { Paired t } \\
(p)\end{array}$ & $\begin{array}{c}\text { Mean } \\
(\mathrm{SD})\end{array}$ & $\begin{array}{c}\text { Paired t } \\
(p)\end{array}$ & $\begin{array}{c}\text { Mean } \\
(\mathrm{SD})\end{array}$ & $\begin{array}{c}\text { Paired t } \\
(p)\end{array}$ \\
\hline \multirow{2}{*}{$\mathrm{a}$ and c } & -3.80 & -2.624 & .45 & 2.910 & .86 & 1.463 \\
& $(5.60)$ & $(.020 *)$ & $(.60)$ & $\left(.011^{*}\right)$ & $(2.29)$ & $(.166)$ \\
\hline \multirow{2}{*}{$\mathrm{c}$ and d } & -.33 & -.295 & -.18 & -1.987 & .20 & .386 \\
& $(4.36)$ & $(.772)$ & $(.35)$ & $(.067)$ & $(2.00)$ & $(.705)$ \\
\hline \multirow{2}{*}{$\mathrm{e}$ and f } & 2.66 & 1.799 & -.05 & -.774 & -.26 & -.604 \\
\hline
\end{tabular}

Note. $\mathrm{a}=$ baseline assessment $; \mathrm{c}=$ post test on step $1 ; \mathrm{d}=$ pre test on step $2 ; \mathrm{e}=$ post test on step $2 ; \mathrm{f}=$ pre test on step 3.

Table 3. Changes in Self- management, Systolic Blood Pressure, Diastolic Blood Pressure, Preferred Salt Concentration and Self- evaluation of Salt Intake in Time Sequence

\begin{tabular}{|c|c|c|c|c|c|c|c|c|c|c|}
\hline \multirow{2}{*}{8} & $\mathrm{a}$ & b & $\mathrm{c}$ & $\mathrm{d}$ & $\mathrm{e}$ & $\mathrm{f}$ & $\mathrm{g}$ & \multirow{2}{*}{$\mathrm{F}$} & \multirow{2}{*}{$p$} & \multirow{2}{*}{$\begin{array}{l}\text { Post } \\
\text { hoc }\end{array}$} \\
\hline & $\mathrm{M}(\mathrm{SD})$ & $\mathrm{M}(\mathrm{SD})$ & $\mathrm{M}(\mathrm{SD})$ & $\mathrm{M}(\mathrm{SD})$ & $\mathrm{M}(\mathrm{SD})$ & $\mathrm{M}(\mathrm{SD})$ & $\mathrm{M}(\mathrm{SD})$ & & & \\
\hline $\begin{array}{c}\text { Self- } \\
\text { managemen } \\
\mathrm{t}\end{array}$ & $\begin{array}{l}62.53 \\
(6.45)\end{array}$ & $\begin{array}{l}64.60 \\
(5.94)\end{array}$ & $\begin{array}{l}66.33 \\
(4.76)\end{array}$ & $\begin{array}{l}66.66 \\
(5.05)\end{array}$ & $\begin{array}{l}68.93 \\
(3.99)\end{array}$ & $\begin{array}{l}66.26 \\
(5.83)\end{array}$ & $\begin{array}{l}66.33 \\
(5.92)\end{array}$ & 3.406 & $\begin{array}{c}.00 \\
5\end{array}$ & $\begin{array}{c}c, d, e, f \\
>a^{*} \\
e>b^{*} \\
e>c^{*}\end{array}$ \\
\hline $\begin{array}{c}\text { Preferred } \\
\text { salt } \\
\text { concentratio } \\
n\end{array}$ & $\begin{array}{c}0.95 \\
(0.55)\end{array}$ & $\begin{array}{c}0.61 \\
(0.21)\end{array}$ & $\begin{array}{c}0.50 \\
(0.26)\end{array}$ & $\begin{array}{c}0.68 \\
(0.26)\end{array}$ & $\begin{array}{c}0.47 \\
(0.19)\end{array}$ & $\begin{array}{c}0.52 \\
(0.19)\end{array}$ & $\begin{array}{c}0.46 \\
(0.18)\end{array}$ & 6.388 & $\begin{array}{c}.00 \\
0\end{array}$ & $\begin{array}{c}a> \\
\mathrm{b}, \mathrm{c}, \mathrm{e}, \mathrm{f}, \\
\mathrm{g}^{*} \\
\mathrm{~b}>\mathrm{e}, \mathrm{g} \\
*\end{array}$ \\
\hline
\end{tabular}




\begin{tabular}{|c|c|c|c|c|c|c|c|c|c|c|}
\hline & & & & & & & & & & $\begin{array}{c}d> \\
e, g^{*}\end{array}$ \\
\hline SBP & $\begin{array}{c}122.0 \\
6 \\
(12.08 \\
)\end{array}$ & $\begin{array}{c}121.6 \\
0 \\
(13.26 \\
)\end{array}$ & $\begin{array}{c}127.6 \\
6 \\
(19.55 \\
)\end{array}$ & $\begin{array}{c}125.2 \\
6 \\
(10.05 \\
)\end{array}$ & $\begin{array}{c}120.5 \\
3 \\
(15.26 \\
)\end{array}$ & $\begin{array}{c}126.2 \\
6 \\
(11.24 \\
)\end{array}$ & $\begin{array}{c}122.7 \\
3 \\
(12.07 \\
)\end{array}$ & .973 & $\begin{array}{c}.44 \\
9\end{array}$ & \\
\hline DBP & $\begin{array}{c}76.33 \\
(11.01 \\
)\end{array}$ & $\begin{array}{l}73.33 \\
(9.28)\end{array}$ & $\begin{array}{c}74.20 \\
(12.68 \\
)\end{array}$ & $\begin{array}{c}73.46 \\
(12.63 \\
)\end{array}$ & $\begin{array}{c}71.00 \\
(11.07 \\
)\end{array}$ & $\begin{array}{l}76.13 \\
(8.93)\end{array}$ & $\begin{array}{l}73.06 \\
(7.79)\end{array}$ & 901 & $\begin{array}{c}.51 \\
7\end{array}$ & $a>e^{*}$ \\
\hline $\begin{array}{c}\text { Self- } \\
\text { evaluation } \\
\text { of salt } \\
\text { intake }\end{array}$ & $\begin{array}{c}4.69 \\
(2.25)\end{array}$ & $\begin{array}{c}3.92 \\
(1.97)\end{array}$ & $\begin{array}{c}3.61 \\
(2.06)\end{array}$ & $\begin{array}{c}3.53 \\
(1.66)\end{array}$ & $\begin{array}{c}3.23 \\
(1.78)\end{array}$ & $\begin{array}{c}3.69 \\
(2.17)\end{array}$ & $\begin{array}{c}3.46 \\
(2.02)\end{array}$ & 1.560 & $\begin{array}{c}.16 \\
9\end{array}$ & $\begin{array}{c}\mathrm{a} \\
>\mathrm{d}, \\
\mathrm{e}, \mathrm{g}\end{array}$ \\
\hline
\end{tabular}

Note. $\mathrm{a}=$ baseline assessment $; \mathrm{b}=$ pre test on $\operatorname{step} 1 ; \mathrm{c}=$ post test on step $1 ; \mathrm{d}=$ pre test on step $2 ; \mathrm{e}=$ post test on step $2 ; \mathrm{f}=$ pre test on step $3 ; \mathrm{g}=$ post test on step $3 ; \mathrm{SBP}=$ systolic blood pressure; $\mathrm{DBP}=$ diastolic blood pressure.

\section{Discussion}

Most participants had blood pressure at a level considered to be under adequate control, but did not have preferred salt concentration level considered to be under adequate control. And most participants had been diagnosed with hypertension and had been prescribed blood pressure medication and other medication for many years. Our research as repeated health education named 3-step health education and tele-coaching program resulted in significant, sustained maintenance in blood pressure control status and sustained improvements in selfmanagement, preferred salt concentration and self-evaluation of salt -intake during 15months continuously. Similarly, the Community-Based Hypertension Control Project showed that individualized counseling and home visits resulted in significant and sustained improvement in blood pressure control status which ranged from $29 \%$ to $41 \% 12$ months follow up assessments [10]. Also, baseline blood pressure of participants was higher than that of our participants in this study. Systematic review on hypertension management which reported from 1990 to 2008 emphasized that health education was the most effective intervention to deal with uncontrolled hypertension [8]. Other program such as home blood pressure monitoring with nurse-led telephone support among patients with hypertension and a history 

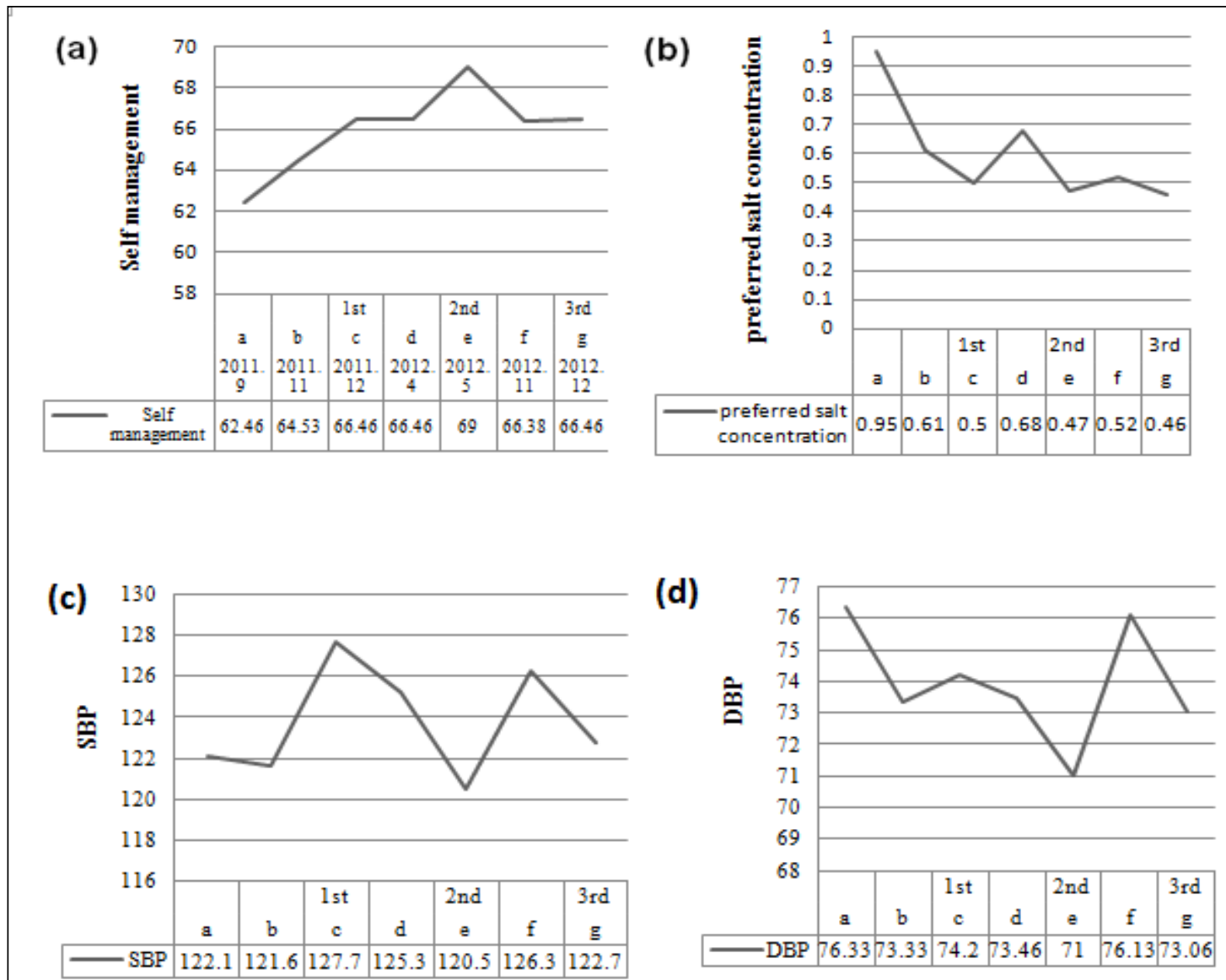

(e)

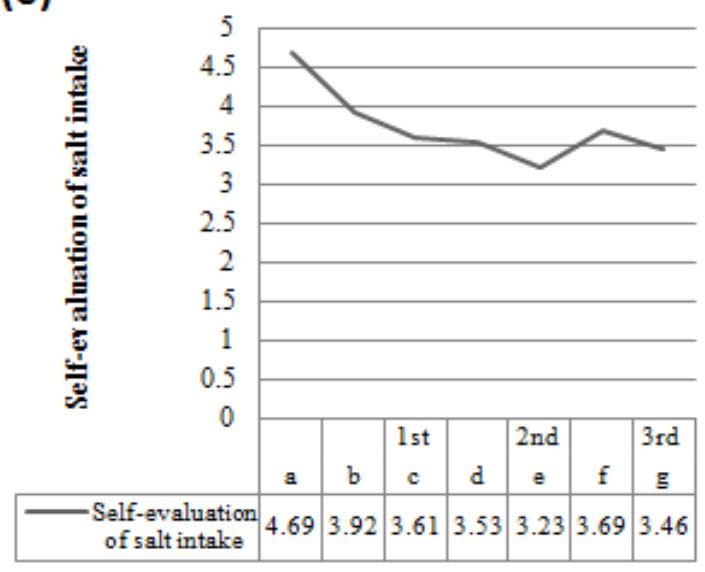

Note. $\mathrm{a}=$ baseline assessment $; \mathrm{b}=$ pre test on $\operatorname{step} 1 ; \mathrm{c}=$ post test on step $1 ; \mathrm{d}=$ pre test on step $2 ; \mathrm{e}=$ post test on step $2 ; \mathrm{f}=$ pre test on step $3 ; \mathrm{g}=$ post test on step $3 ; \mathrm{SBP}=$ systolic blood pressure; DBP $=$ diastolic blood pressure.

Figure 1. Changes in Study Outcomes from Baseline Assessment to 15 Months;

(a) Self- management ; (b) Preferred Salt Concentration ; (c) Systolic Blood Pressure ; (d) Diastolic Blood Pressure 
of stroke, did not improve blood pressure control [6]. Other studies also demonstrated that education programs may result in high adherence to antihypertensive treatments, which is associated with better blood pressure control [4]. Other research as self-care program composed of 3 times for 3 weeks health education, 9 times for 9weeks tele-counseling and 11 times for 11 weeks continuing self-care induction resulted in only low sodium intake and systolic blood pressure control [14]. Specially, most individuals with developmental disabilities did not receive the services that their health condition requirements [1], as well as in our research findings disabled people with chronic health problems in rural region did not receive the more suitable services. A research of the rehabilitation services utilization of people with disabilities in Korean rural region showed that $70.3 \%$ were using rehabilitation services such as treatments, physical therapy and others but only $19.3 \%$ of respondents were satisfied with the service [3].

Therefore the findings of this study suggest the importance of applying tailored interventions to manage effectively individual specific demands such as risk factors of high blood pressure and recommend to provide at least for 12 months. Further, health care professionals and health educators must be consider other risk factors such as seasonal effect on changes in blood pressure and health illiteracy when designing therapeutic interventions for hypertension.

\section{Conclusion}

The tailored program, the three-step health education and tele-coaching program, for people with disability was effective in enhancing self-management and behavioral change for the disabled people with hypertension. And we recommend step by step health education and tele-coaching programs for the elderly with disabilities to promote life style modification for managing hypertension. The patients with chronic disease need repeated education for at least a year to improve their health related behaviors.

\section{References}

[1] S. M. Havercamp, D. Scandlin and M. Roth, "Health Disparities among Adults with Developmental Disabilities, Adultswith other Disabilities, and Adults not Reporting Disability in North Carolina", Public Health Reports", vol. 119, no. 4, (2004), pp. 418-426.

[2] Korea Institute for Health and Social Affairs, https://www.kihasa.re.kr/.

[3] G. J. Choi, K. Y. Kim, D. H. Lee, C. H. Han and S. M. Choi, "The Rehabilitation Services Utilization of People with Disabilities in a Rural Area. Journal of Agricultural Medicine and Community Health", vol. 36, no. 4, (2011), pp. 227-237.

[4] T. A. Lauzière, N. Chevarie, M. Poirier, A. Utzschneider and M. Bélanger, "Effects of an Interdisciplinary Education Program on Hypertension:A Pilot Study. Canadian Journal of Cardiovascular Nursing”, vol. 23, no. 1, (2013), pp. 12-18.

[5] "PROGRESS Collaborative Group: Randomized Trial of a Perindopril-based Blood-pressure-lowering Regimen among 6105 Individuals with Previous Stroke or Transient Ischemic Attack. Lancet”, vol. 358, (2001), pp. 1033-1041.

[6] S. M. Kerry, H. S. Markus, T. K. Khong, G. C. Cloud, J. Tulloch, D. Coster, J. Ibison and P. Oakeshott, "Home Blood Pressure Monitoring with Nurse-led Telephone Support among Patients with Hypertension and a History of Stroke: a Community-based Randomized Controlled Trial”, Canadian Medical Association Journal, vol. 185, no. 1, (2013), pp. 23-31.

[7] G. Parati and T. G. Pickering, "Home Blood-pressure Monitoring: US and European Consensus. Lancet", vol. 373, no. 9667, (2009), pp. 876-878.

[8] C. B. Kim, M. Y. Kim, J. E. Lee, S. Y. Kim and H. S. Ahn, "Are the Interventions of Health Promotion Effective for Hypertension Management?: Systematic Review Approach on International Articles of Nutrition, Exercise, and Health Education", Proceeding of Conference of Korean Academy of Health Policy and Management, (2008), pp. 375-376. 
[9] J. B. Brill, "Lifestyle Intervention Strategies for the Prevention and Treatment of Hypertension: A Review", American Journal of Lifestyle Medicine, vol. 5, no. 4, (2011), pp. 346-360.

[10] D. E. Morisky, , N. B. Lees, B. A. Sharif , K. Y. Liu, , H. J. Ward, "Reducing Disparities in Hypertension Control: A Community-Based Hypertension Control Project (CHIP) for an Ethnically Diverse Population', Health Promotion Practice, vol. 3, no. 2, (2002), pp. 264-275.

[11] S. L. Nine, C. L. Lakies, H. K.Jarrett and B. A. Davis, "Community-based Chronic Disease Management Program for Afrian Americans, Outcomes Management, Lippincott Williams \& Wilkins”, vol. 7, no. 3, (2003), pp. 106-112.

[12] E. M. Duff and R. Wilks, "Six-month Hypertension Intervention Study. One Year Follow-up", West Indian Medical Journal, University of the West Indies, vol. 52, no. 3, pp. 219-222, (2003).

[13] P. Connell, C. Wolfe and C. McKevitt, "Preventing Stroke: a Narrative Review of Community Intervention for Improving Hypertension Control in Black Adults", Health and Social Care in the Community, Blackwell, vol.16 2, (2008), pp. 165-187.

[14] O. R. Kim, "Effects of Self Care Program on Hypertensive Control in Hypertensive Patient", J Korean Acad. Community Health Nurs., vol. 14, no. 4, (2003), pp. 568-578.

[15] J. H. Park, Y. S. Shin, S. Y. Lee and J. H. Park, "Antihypertensive Drug Medication Adherence of People with Disabilities and its Affecting Factors in Korea", Journal of Preventive Medicine and Public Health, vol. 40, no. 3, (2007), pp. 249-258. 